\title{
Genetic variants associated with breast size also influence breast cancer risk
}

\author{
Nicholas Eriksson ${ }^{*}$, Geoffrey M Benton, Chuong B Do, Amy K Kiefer, Joanna L Mountain, David A Hinds, Uta \\ Francke and Joyce Y Tung
}

\begin{abstract}
Background: While some factors of breast morphology, such as density, are directly implicated in breast cancer, the relationship between breast size and cancer is less clear. Breast size is moderately heritable, yet the genetic variants leading to differences in breast size have not been identified.

Methods: To investigate the genetic factors underlying breast size, we conducted a genome-wide association study (GWAS) of self-reported bra cup size, controlling for age, genetic ancestry, breast surgeries, pregnancy history and bra band size, in a cohort of 16,175 women of European ancestry.

Results: We identified seven single-nucleotide polymorphisms (SNPs) significantly associated with breast size $\left(p<5 \cdot 10^{-8}\right)$ : rs7816345 near ZNF703, rs4849887 and (independently) rs17625845 flanking INHBB, rs 12173570 near ESR1, rs7089814 in ZNF365, rs12371778 near PTHLH, and rs62314947 near AREG. Two of these seven SNPs are in linkage disequilibrium (LD) with SNPs associated with breast cancer (those near ESR1 and PTHLH), and a third (ZNF365) is near, but not in LD with, a breast cancer SNP. The other three loci (ZNF703, INHBB, and AREG) have strong links to breast cancer, estrogen regulation, and breast development.

Conclusions: These results provide insight into the genetic factors underlying normal breast development and show that some of these factors are shared with breast cancer. While these results do not directly support any possible epidemiological relationships between breast size and cancer, this study may contribute to a better understanding of the subtle interactions between breast morphology and breast cancer risk.
\end{abstract}

\section{Background}

Breast morphology plays a complicated role in breast cancer risk. Most strikingly, mammographic density (the percent of non-fat breast tissue measured in a mammogram) is a risk factor for breast cancer [1]. Body weight, which is positively correlated with breast size, also has a complex relationship with breast cancer risk. Higher weight at younger ages decreases both premenopausal and postmenopausal breast cancer risk [2,3], while weight gain in adulthood increases postmenopausal breast cancer risk $[4,5]$. Breast asymmetry may also be associated with breast cancer risk [6]. The relationship between breast size and cancer is not entirely clear. Two studies have found that, for lean women, larger breast size is associated with a higher risk of breast cancer $[7,8]$. For example, Kusano et al. [7] found that among women with a BMI under

*Correspondence: nick@23andme.com

23andMe, Inc., Mountain View, CA 94043, USA
25 , those with a cup size of D or larger had a 1.8 times higher risk of breast cancer than those with a cup size of $\mathrm{A}$ or smaller.

Genetic factors also play a role in breast cancer risk, with many genetic associations discovered to date. In contrast, there have been no genetic studies of breast size and only one GWAS of breast density [9]. Twin studies have shown that breast size is about $56 \%$ heritable, with only about a third of this heritability shared with the heritability of obesity [10]. However, to date, nothing is known about what genetic factors are associated with breast size. In this study, we examine the genetic factors underlying breast size through a GWAS of self-reported bra cup size in a cohort of 16,175 women of European ancestry. Of the seven significant associations we find with breast size, two are shared with breast cancer. In both cases, the same allele is linked to both increased breast size and increased breast cancer risk. A third breast size association is near a SNP associated with breast cancer risk and breast density, 
and the others are near genes with links to breast cancer and mammary development.

\section{Methods}

\section{Subjects}

Participants were drawn from the customer base of 23andMe, Inc., a consumer genetics company. This cohort has been described in detail previously [11,12]. All participants were female, of European ancestry, and no two shared more than $700 \mathrm{cM}$ of DNA identical by descent (IBD, approximately the lower end of sharing between a pair of first cousins). IBD was calculated using the methods described in [13] and European individuals were selected as in [14]. Participants provided informed consent and participated in the research online, under a protocol approved by the external AAHRPP-accredited IRB, Ethical and Independent Review Services (E\&I Review).

\section{Genotyping}

Subjects were genotyped on one or more of three chips, two based on the Illumina HumanHap550+ BeadChip, the third based on the Illumina OmniExpress+ BeadChip. The platforms contained 586,916, 584,942, and 1,008,948 SNPs. Totals of 142, 4,764, and 11,890 participants were genotyped on the platforms, respectively. A total of 621 individuals were genotyped on multiple chips. For all participants, we imputed genotypes against the August 2010 release of the 1000 Genomes reference haplotypes [15]. First, we used Beagle 3.3.1 [16] to phase batches of 8000-9000 individuals across chromosomal segments of no more than 10,000 genotyped SNPs, with overlaps of 100 SNPs. Individuals were grouped by genotyping array before this phasing, which was performed on the entire 23andMe cohort. Across this larger cohort, a total of ten batches were run, four consisting of individuals typed on the first two platforms and the other six of individuals typed on the third platform. Before phasing, we excluded SNPs with minor allele frequency under 0.001, $p$-value for Hardy-Weinberg equilibrium under $10^{-20}$, or call rate under 95\%. The threshold for the Hardy-Weinberg test is smaller than usual because the $p$-values were computed in a sample of nearly 100,000 European individuals; our threshold of $10^{-20}$ corresponds roughly to a threshold of $10^{-4}$ for a sample size of 20,000 individuals. We also excluded SNPs with large allele frequency discrepancies compared to the 1000 Genomes reference data. We then assembled full phased chromosomes by matching the phase of haplotypes across the overlapping segments. We imputed each batch against the European subset of 1000 Genomes haplotypes with Minimac [17], using 5 rounds and 200 states for parameter estimation. A total of 11,914,767 SNPs were imputed. Of these, 7,422,970 met our thresholds of 0.001 minor allele frequency and $r^{2}$ of at least 0.5 (averaged across batches).
Imputation quality was slightly higher overall for the batches using the denser platform (average $r^{2}$ of 0.91 versus 0.87 ). In the tables, we thus report the $r^{2}$ separately for the first four batches and the last six batches (denoted $r_{V 2}^{2}$ and $r_{V 3}^{2}$, respectively). The overall $r^{2}$ can be calculated as $r^{2}=0.45 \cdot r_{V 2}^{2}+0.55 \cdot r_{V 3}^{2} \cdot p$-values for Hardy-Weinberg equilibrium were calculated using the test from [18] on dosages rounded to the nearest integer (set to NA if the dosage was more than 0.25 away from an integer). Positions and alleles are given relative to the positive strand of build 37 of the human genome.

\section{Phenotype data collection}

All participants reported bra cup size and bra band size as part of an online body morphology questionnaire. Participants selected a cup size from nine categories and entered band size as an integer. Those entering a band size of over 70 were assumed to be using centimeters and were removed from analysis.

Subsets of participants also reported other phenotypes. As covariates in the analysis, we included the projections onto the first five principal components of genetic ancestry as well as age, bra band size (in inches), and indicator variables for breast augmentation surgery, breast reduction surgery, mastectomy, past pregnancy, and current pregnancy or breastfeeding. Out of the 16,175 participants, all but 3 reported age, over 15,000 reported bra band size, about 12,000 reported breast surgery status (augmentation, reduction, mastectomy, or none), about 6,000 reported if they had ever been pregnant, and 4,000 reported if they were currently pregnant or breastfeeding.

Band size was used as a covariate instead of BMI because while almost every participant reported band size, only about half reported BMI. Band size has previously been used as a proxy for BMI in breast size research [8]. The correlation between BMI and band size in our sample was over 0.5 . Furthermore, although bra size is easy to report, it is not a perfect proxy for actual breast volume. There is evidence that controlling for bra band size improves the correlation between cup size and breast volume [19].

\section{Statistical analysis}

Bra size was coded from 0 to 9 , corresponding to the categories: Smaller than AAA, AAA, AA, A, B, C, D, DD, DDD, and Larger than DDD, respectively. Mean size was 4.99 (just under a "C" cup) and the standard deviation was 1.45. Genotypes were coded as dosages from $0-2$, corresponding to the estimated number of copies of the minor allele present. $p$-values for SNPs were calculated using likelihood ratio tests for linear regressions.

The principal component analysis was done as described before [11]. Individuals who were missing some of the covariates were imputed to the average value 
among those who did provide data. Average values for age and bra band size were 47.4 years and 36.2 inches, respectively. The percentages answering "yes" to other covariates were: breast augmentation, $5 \%$; breast reduction, 3\%; mastectomy, 1.7\%; ever pregnant, $80 \%$; and currently pregnant or breastfeeding, $3 \%$.

On average, those reporting augmentation reported 0.5 size smaller breasts, reduction 1 size bigger, mastectomy 0.5 size smaller, and ever pregnant 0.1 size bigger. For every inch of band size, cup size was reported to be 0.1 sizes bigger on average. Current pregnancy did not significantly influence reported cup size. Some participants commented that they reported their pre-surgery or prepregnancy breast size. As those reporting augmentation also reported smaller breasts on average, it may be the case that many participants reported pre-surgery size. If that is the case generally, including these covariates just led to decreased power. We looked at effect sizes for the SNPs in Table 1 with and without including the covariates beyond age and PCs and saw no significant differences in effect sizes.

We performed conditional analyses within each genome-wide significant region to search for SNPs with independent effects. We analyzed each SNP within $500 \mathrm{~kb}$ from each index SNP, adding the index SNP to the covariates for this analysis (and continuing the process iteratively if any SNPs remained with a $p$-value of $10^{-6}$ ).

\section{Results and discussion}

We identified six regions containing SNPs significantly associated with breast size (using a threshold of $5 \cdot 10^{-8}$ for genome-wide significance), see Figure 1 . The genomic control inflation factor for this study was 1.047 (see Additional file 1 for the quantile-quantile plot).
The SNPs with the smallest $p$-values in these regions are rs7816345 in 8p12 (a region that is amplified in breast tumors and contains the breast cancer oncogene ZNF703 (zinc finger protein 703)), rs4849887 near INHBB (inhibin, beta B), rs12173570 near ESR1 (estrogen receptor 1), rs7089814 in ZNF365 (zinc finger protein 365), rs12371778 near PTHLH (parathyroid hormone-like hormone), and rs62314947 near AREG (amphiregulin); see Table 1 for details and Figure 2 for plots of $p$-values in these regions. All SNPs with $p$-values under $10^{-4}$ are shown in Additional file 2.

First, rs7816345 $\left(p=1.64 \cdot 10^{-13}\right)$, lies within the $8 \mathrm{p} 12$ region commonly amplified in the luminal $B$ subtype of estrogen receptor (ER) positive breast cancers that have a poor clinical outcome [20]. ZNF703, the only gene in the minimal amplified region, is the likely oncogene driving this amplification [21]. ZNF703 is up-regulated by estrogen and is a co-factor for a nuclear repressor complex that plays a role in the regulation of ER activity. It has also been implicated in the regulation of cell proliferation, and its overexpression leads to an increase in breast cancer stem cells [21,22]. Interestingly, ZNF703 exerts a downstream effect on the TGF beta signaling pathway [22] and also cooperates with a form of $\mathrm{p} 53$ [23].

rs4849887 $\left(p=3.31 \cdot 10^{-11}\right)$ lies $140 \mathrm{~kb}$ downstream of the closest gene, INHBB. INHBB is a subunit of both inhibin and activin, hormones in the TGF beta superfamily that are important for many endocrine functions. While both $I N H B A$ (inhibin, beta A) and $I N H B B$ are expressed in normal breast tissue, only $I N H B B$ is upregulated by estrogen [24]. Activin A (an inhibin beta A homodimer) is more highly expressed in breast cancer [25], though $I N H B B$ has been implicated in the carcinogenesis of non-endometrial uterine cancer [26]. INHBB is also highly expressed in fat cells, and its expression

Table 1 Index SNPs for regions under $p=10^{-6}$

\begin{tabular}{ccccccccccc}
\hline SNP & Chr & Position & Gene & Allele & MAF & HWE & $\boldsymbol{r}_{\boldsymbol{V} \mathbf{2}}^{2}$ & $\boldsymbol{r}_{\boldsymbol{V} \mathbf{3}}^{2}$ & $\boldsymbol{p}$-value & $\boldsymbol{\beta}$ \\
\hline rs7816345 & 8 & 36846109 & ZNF703 & C/T & 0.194 & 0.08 & 1.00 & 1.00 & $1.64 \cdot 10^{-14}$ & $-0.151(-0.189--0.112)$ \\
rs4849887 & 2 & 121245122 & INHBB & C/T & 0.113 & 0.97 & 1.00 & 0.94 & $3.31 \cdot 10^{-11}$ & $0.166(0.117-0.214)$ \\
rs17625845 & 2 & 121089731 & INHBB & T/C & 0.205 & 0.07 & 0.72 & 0.99 & $4.7 \cdot 10^{-10}$ & $0.125(0.086-0.164)$ \\
rs12173570 & 6 & 151957714 & ESR1 & C/T & 0.101 & 0.82 & 0.98 & 0.99 & $5.58 \cdot 10^{-11}$ & $0.171(0.120-0.222)$ \\
rs7089814 & 10 & 64187564 & ZNF365 & T/C & 0.375 & 0.97 & 0.94 & 0.98 & $3.3 \cdot 10^{-9}$ & $0.096(0.064-0.128)$ \\
rs12371778 & 12 & 28156081 & PTHLH & C/G & 0.091 & 0.72 & 0.85 & 0.87 & $1.03 \cdot 10^{-8}$ & $-0.162(-0.217--0.106)$ \\
rs62314947 & 4 & 75502487 & AREG & C/T & 0.281 & 0.31 & 0.73 & 0.91 & $4.79 \cdot 10^{-8}$ & $-0.101(-0.137--0.065)$ \\
rs4820792 & 22 & 29161007 & CHEK2 & C/T & 0.180 & 0.01 & 0.95 & 0.97 & $4.17 \cdot 10^{-7}$ & $0.105(0.065-0.146)$ \\
chr22:40779964 & 22 & 40779964 & MKL1 & G/A & 0.056 & 0.05 & 0.75 & 0.78 & $5.47 \cdot 10^{-7}$ & $-0.187(-0.261--0.114)$ \\
rs61280460 & 14 & 94796184 & SERPINA6 & A/T & 0.199 & 0.29 & 1.00 & 1.00 & $8.3 \cdot 10^{-7}$ & $-0.095(-0.132--0.057)$ \\
\hline
\end{tabular}

The index SNP is defined as the SNP with the smallest $p$-value within a region; or the SNP with the smallest $p$-value in the conditional analysis. The listed gene is our postulated candidate gene near the SNP. For INHBB, conditional analysis revealed two independent SNPs in the region. Alleles are listed as major/minor (in Europeans). MAF is the frequency of the minor allele in Europeans and $r_{V 2}^{2}$ and $r_{V 3}^{2}$ are the estimated imputation accuracies on the two genotyping platforms. HWE is the $p$-value for Hardy-Weinberg equilibrium (calculated on rounded dosages). The coefficient $\beta$ refers to the average change in breast size (in units of cup size) per copy of the minor allele. 


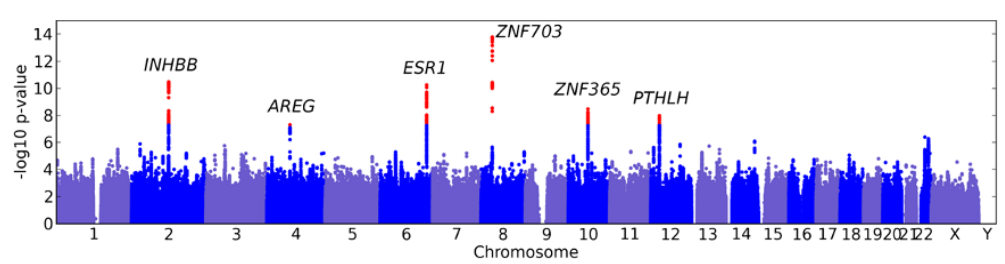

Figure 1 Manhattan plot of association with breast size. $-\log _{10} p$-values across all SNPs tested. SNPs shown in red are genome-wide significant $\left(p<5 \cdot 10^{-8}\right)$. Regions are named with the postulated candidate gene.

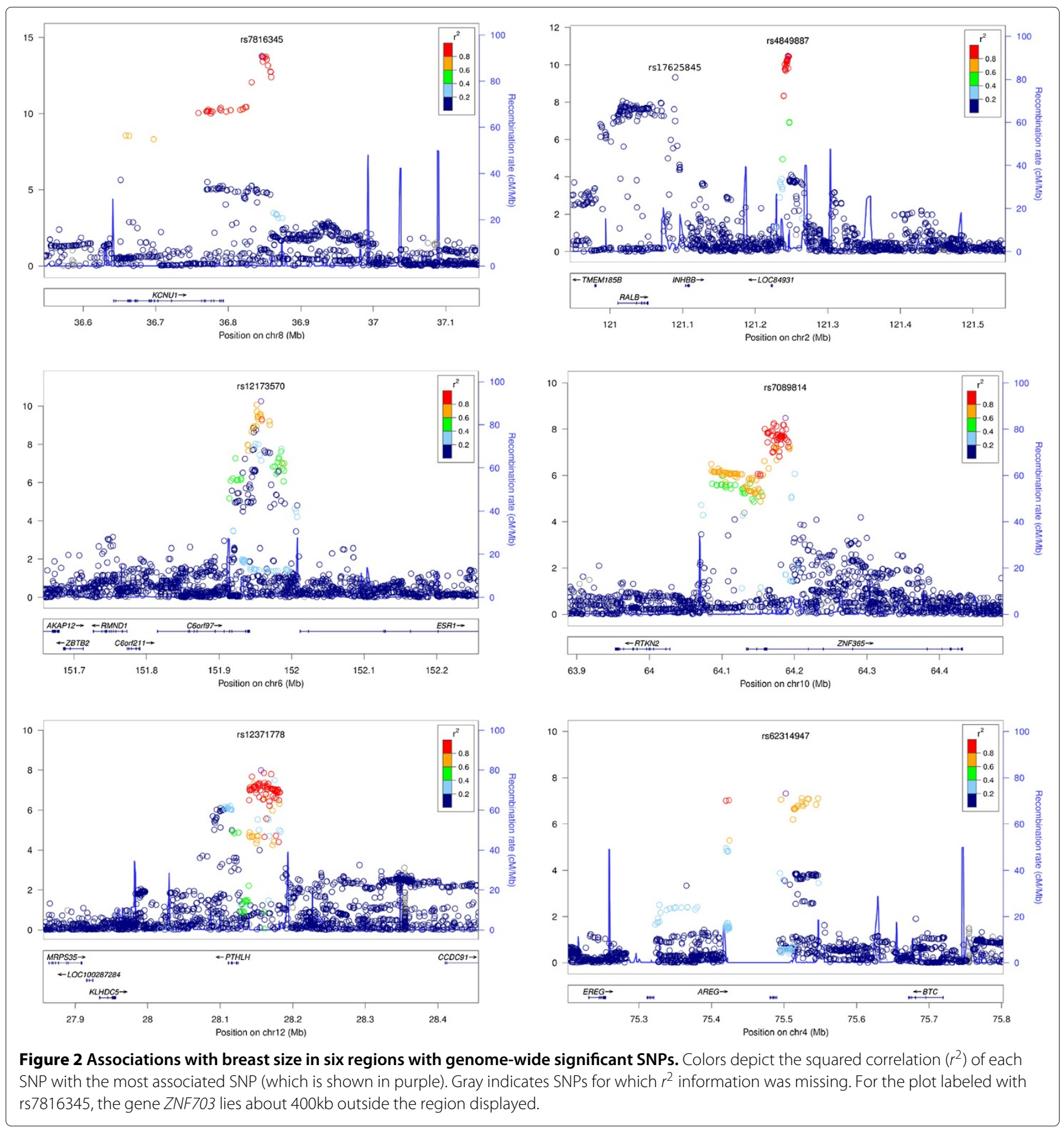


is reduced by weight loss [27]. A conditional analysis in this region, controlling for rs4849887, revealed a second, independent association with breast size: rs17625845 ( $p$ value $4.7 \cdot 10^{-10}$ in the initial analysis and $5.85 \cdot 10^{-10}$ controlling for rs4849887). This SNP is located upstream of $I N H B B$.

The next SNP association with breast size is rs12173570, located near ESR1, $\left(p=5.58 \cdot 10^{-11}\right)$. rs12173570 is in LD with rs9397435 $\left(r^{2}=0.56\right)$, which is also associated with breast size $\left(p=1.15 \cdot 10^{-9}\right)$. rs9397435 has previously been associated with breast cancer in European, Asian, and African populations and affects the expression of ESR1 [28]. The G allele of rs 9397435 corresponds to larger breast size, increased cancer risk, and increased expression. ESR1 is of great importance in normal breast development and cancer, and there is evidence that rs 2046210 (which is in LD with rs9397435 in Asian populations $\left(r^{2}=\right.$
$0.73)$ but less so in European populations $\left.\left(r^{2}=0.13\right)\right)$ may be associated with breast density [9].

The fourth region associated with breast size is centered around ZNF365 (rs7089814, $p=3.30 \cdot 10^{-9}$ ). This SNP lies in an intron of ZNF365, about 90kb away from rs10995190. rs10995190 has been associated with both breast cancer [29] and breast density [9]. rs7089814 and rs10995190 are not in $\mathrm{LD}\left(r^{2}=0.035\right)$, and there is some evidence that rs10995190 is associated with breast size independently from rs7089814 $\left(p=8.5 \cdot 10^{-4}\right.$ initially (Table 2) and $1.7 \cdot 10^{-3}$ after correction for rs7089814).

rs12371778, near $P T H L H$, is associated with breast size $\left(p=1.03 \cdot 10^{-8}\right)$, and is in $\operatorname{LD}\left(r^{2}=0.82\right)$ with rs10771399, which has previously been associated with breast cancer [30]. The A allele of rs10771399 is the risk allele for breast cancer and corresponds to the $\mathrm{C}$ allele of rs12371778, which is associated with larger breast

Table 2 Association with breast size for SNPs previously associated with breast cancer

\begin{tabular}{|c|c|c|c|c|c|c|c|c|c|c|}
\hline SNP & Chr & Position & Gene & Allele & MAF & HWE & $r_{V 2}^{2}$ & $r_{V 3}^{2}$ & $p$-value & $\beta$ \\
\hline rs9397435 & 6 & 151951220 & ESR1 & $A / G$ & 0.080 & 0.34 & 0.93 & 0.94 & $1.14 \cdot 10^{-9}$ & $0.183(0.124-0.242)$ \\
\hline rs2046210 & 6 & 151948366 & ESR1 & $\mathrm{G} / \mathrm{A}$ & 0.355 & 0.89 & 0.97 & 1.00 & $1.33 \cdot 10^{-8}$ & $0.092(0.060-0.124)$ \\
\hline rs10771399 & 12 & 28155080 & PTHLH & $A / G$ & 0.111 & 0.50 & 0.94 & 0.99 & $5.87 \cdot 10^{-8}$ & $-0.133(-0.181--0.085)$ \\
\hline rs10995190 & 10 & 64278682 & ZNF365 & $\mathrm{G} / \mathrm{A}$ & 0.155 & 0.15 & 1.00 & 1.00 & 0.000857 & $-0.071(-0.113--0.029)$ \\
\hline rs3803662 & 16 & 52586341 & TOX3 & $\mathrm{G} / \mathrm{A}$ & 0.276 & 0.16 & 1.00 & 1.00 & 0.0225 & $0.040(0.006-0.074)$ \\
\hline rs3817198 & 11 & 1909006 & LSP1 & $\mathrm{T} / \mathrm{C}$ & 0.324 & 0.13 & 1.00 & 1.00 & 0.0632 & $0.031(-0.002-0.063)$ \\
\hline rs2823093 & 21 & 16520832 & $21 q 21$ & $\mathrm{G} / \mathrm{A}$ & 0.273 & 0.23 & 1.00 & 1.00 & 0.133 & $0.026(-0.008-0.060)$ \\
\hline rs16886165 & 5 & 56023083 & MAP3K1 & $\mathrm{T} / \mathrm{G}$ & 0.158 & 0.95 & 1.00 & 1.00 & 0.137 & $-0.031(-0.073-0.010)$ \\
\hline rs981782 & 5 & 45285718 & $5 p 12$ & $\mathrm{~A} / \mathrm{C}$ & 0.455 & 0.03 & 1.00 & 1.00 & 0.146 & $0.022(-0.008-0.053)$ \\
\hline rs10941679 & 5 & 44706498 & $5 p 12$ & $A / G$ & 0.241 & 0.06 & 0.66 & 1.00 & 0.158 & $0.027(-0.010-0.064)$ \\
\hline rs999737 & 14 & 69034682 & RAD51L1 & $\mathrm{C} / \mathrm{T}$ & 0.226 & 0.69 & 1.00 & 1.00 & 0.182 & $-0.025(-0.061-0.012)$ \\
\hline rs889312 & 5 & 56031884 & MAP3K1 & $A / C$ & 0.286 & 0.27 & 1.00 & 1.00 & 0.221 & $-0.021(-0.054-0.013)$ \\
\hline rs1219648 & 10 & 123346190 & FGFR2 & $A / G$ & 0.402 & 0.65 & 1.00 & 1.00 & 0.223 & $0.019(-0.012-0.050)$ \\
\hline rs2981582 & 10 & 123352317 & FGFR2 & $\mathrm{G} / \mathrm{A}$ & 0.397 & 0.79 & 1.00 & 1.00 & 0.304 & $0.016(-0.015-0.047)$ \\
\hline rs1562430 & 8 & 128387852 & $8 q 24.21$ & $\mathrm{~T} / \mathrm{C}$ & 0.423 & 0.03 & 1.00 & 1.00 & 0.308 & $-0.016(-0.046-0.015)$ \\
\hline rs6504950 & 17 & 53056471 & $17 q 23.2$ & $\mathrm{G} / \mathrm{A}$ & 0.274 & 0.89 & 1.00 & 1.00 & 0.317 & $0.017(-0.017-0.051)$ \\
\hline rs7222197 & 17 & 53047499 & STXBP4 & G/A & 0.274 & 0.91 & 1.00 & 1.00 & 0.317 & $0.017(-0.017-0.051)$ \\
\hline rs2380205 & 10 & 5886734 & ANKRD16 & $C / T$ & 0.428 & 0.10 & 1.00 & 1.00 & 0.327 & $0.015(-0.015-0.046)$ \\
\hline rs2981579 & 10 & 123337335 & FGFR2 & $\mathrm{G} / \mathrm{A}$ & 0.416 & 0.26 & 1.00 & 1.00 & 0.339 & $0.015(-0.016-0.046)$ \\
\hline rs704010 & 10 & 80841148 & ZMIZ1 & $\mathrm{C} / \mathrm{T}$ & 0.379 & 0.32 & 1.00 & 1.00 & 0.418 & $0.013(-0.018-0.044)$ \\
\hline rs1292011 & 12 & 115836522 & $12 q 24$ & $A / G$ & 0.422 & 0.70 & 0.99 & 1.00 & 0.428 & $-0.012(-0.043-0.018)$ \\
\hline rs1045485 & 2 & 202149589 & CASP8 & $\mathrm{G} / \mathrm{C}$ & 0.123 & 0.92 & 1.00 & 1.00 & 0.472 & $-0.017(-0.062-0.029)$ \\
\hline rs614367 & 11 & 69328764 & MYEOV & $C / T$ & 0.149 & 0.42 & 0.98 & 0.99 & 0.525 & $-0.014(-0.057-0.029)$ \\
\hline rs1011970 & 9 & 22062134 & CDKN2A & $\mathrm{G} / \mathrm{T}$ & 0.171 & 0.12 & 1.00 & 1.00 & 0.589 & $0.011(-0.029-0.051)$ \\
\hline rs4973768 & 3 & 27416013 & $3 p 24$ & $C / T$ & 0.485 & 0.26 & 1.00 & 1.00 & 0.591 & $0.008(-0.022-0.038)$ \\
\hline rs13387042 & 2 & 217905832 & $2 q 35$ & $A / G$ & 0.476 & 0.60 & 1.00 & 1.00 & 0.613 & $0.008(-0.023-0.038)$ \\
\hline rs11249433 & 1 & 121280613 & $1 p 11.2$ & $A / G$ & 0.424 & 0.05 & 0.94 & 0.95 & 0.744 & $-0.005(-0.037-0.026)$ \\
\hline rs13281615 & 8 & 128355618 & $8 q 24.21$ & $A / G$ & 0.416 & 0.06 & 1.00 & 1.00 & 0.976 & $0.000(-0.030-0.031)$ \\
\hline
\end{tabular}

Columns are as in Table 1. 
size. PTHLH encodes a member of the parathyroid hormone family that plays a key role in embryonic mammary development [31] as well as lactation [32].

Finally, rs62314947, $p=4.79 \cdot 10^{-8}$, near AREG, barely falls under our threshold for genome-wide significance. Amphiregulin is related to the epidermal growth factor and TGF alpha families. It mediates ER function in mammary development [33,34].

Three SNPs have $p$-values under $10^{-6}$ but are not genome-wide significant (Additional file 3). First, rs4820792 $\left(p=4.17 \cdot 10^{-7}\right)$ lies $25 \mathrm{~kb}$ upstream of CHEK2 (checkpoint kinase 2), which is involved in the response to DNA damage. The 1100delC mutation in CHEK2 is strongly associated with breast cancer; however, $1100 \mathrm{delC}$ and rs4820792 are not in LD. Next, chr22:40779964 ( $p=$ $5.47 \cdot 10^{-7}$ ) lies in SGSM3 (small G protein signaling modulator 3), near $M K L 1$, megakaryoblastic leukemia (translocation) 1 . Finally, rs61280460 $\left(p=8.30 \cdot 10^{-7}\right)$ lies near SERPINA6 (serpin peptidase inhibitor, clade A (alpha-1 antiproteinase, antitrypsin), member 6).

Motivated by the above overlaps between breast cancer and breast size SNPs, we analyzed 29 SNPs that have previously been associated with breast cancer (from [29,30] and the supplement of [9]) for association with breast size in our data (Table 2). Of these 29 SNPs, only four were significant after correcting for 29 tests; these are the SNPs mentioned above near ESR1 (two SNPs), PTHLH, and ZNF365.

There is a strong relationship in our data between BMI and breast size-each additional BMI unit corresponds to an increase of about 0.1 cup sizes on average. However, the SNPs in Table 1 are not in LD with any variants previously associated with BMI [35]; this is expected due to the inclusion of bra band size (which is correlated with BMI) as a covariate. Furthermore, even if we did not control for BMI, the strongest associations with BMI (e.g., rs1558902 near FTO) have effects of about 0.4 BMI units per allele. This would correspond to an expected $\beta$ of about 0.04 for breast size for these SNPs, which is below the effect sizes we are powered to detect here. Indeed, if bra band size is not included as a covariate, rs 1558902 has an estimated $\beta$ of 0.07 (95\% CI: $0.04-0.10$ ) for breast size and $p$-value of $8 \cdot 10^{-6}$ as compared to $\beta$ of 0.04 (95\% CI: $0.01-0.07$ ) with bra band size included.

The covariates included in the analysis explain about 9.7\% of the variance in breast size in our data; including the 7 SNPs in Table 1 that are genome-wide significant increases this to $10.9 \%$. We used these 7 SNPs to compute a genetic propensity score for breast size by counting the number of alleles associated with larger size that each participant carried. The average cup size among women in the top $5 \%$ of this score (women carrying 9 or more of the 14 possible "large" alleles) was 0.83 cup sizes bigger (5.39 versus 4.56$)$ than the average cup size among women in the bottom $5 \%$ of this score (women carrying 4 or fewer "large" alleles).

We note that the estimation of breast volume via selfreported bra size is likely to be far from perfect. Thus, it would be interesting to see what effects the SNPs found here would have in a more exactly phenotyped population. Likewise, many of the SNPs reported here were only imputed and not directly typed. While the estimated $r^{2}$ values are generally quite high, indicating good imputation quality, ideally these SNPs would be directly typed in a replication cohort.

\section{Conclusions}

Surprisingly, this GWAS demonstrates that variants in some of the same gene regions are involved in both breast size and breast cancer. We have shown that two SNPs (rs12173570 near ESR1 and rs12371778 near PTHLH) are associated with breast size; these two SNPs have previously been associated with breast cancer risk. A third SNP previously associated with breast cancer, rs10995190 in ZNF365, shows a possible association with breast size; in addition, we find a second SNP in the same gene (rs7089814) that is significantly associated with breast size. It should be noted that the shared relationships between breast size and breast cancer at these three regions are not strong enough to account for the possible epidemiological connection that has been reported elsewhere between breast size and breast cancer.

The other associations we have found are near genes involved in other aspects of breast cancer and estrogen pathways. We find two independent associations with size flanking the gene $I N H B B$, which has connections to estrogen regulation, obesity, and uterine cancer. Of the final two associations, one lies in the $8 \mathrm{p} 12$ region amplified in breast tumors (near ZNF703) and the last lies near $A R E G$, which plays a role mediating estrogen function in breast development.

Our results identify genetic variants that have an effect on both breast cancer and natural variation in breast size. While the precise relationships between breast size, density, obesity and breast cancer remain difficult to untangle, understanding the biology behind these developmental processes may be important in understanding breast cancer and may aid in the development of novel screening tools.

\section{Additional files}

Additional file 1: Quantile-quantile plot of association with breast size. Observed $p$-values versus theoretical $p$-values under the null hypothesis of no association. The genomic control inflation factor for the study was 1.047 and is indicated by the red line; approximate $95 \%$ confidence intervals are given by the blue curves. 
Additional file 2: All SNPs with $p<10^{-4}$ for breast size. Alleles are listed as major/minor. MAF is the frequency of the minor allele in Europeans, and $r_{V 2}^{2}$ and $r_{V 3}^{2}$ are the estimated imputation accuracies on the two genotyping platforms.

Additional file 3: Associations with breast size in three regions with suggestive SNPs. Colors depict the squared correlation $\left(r^{2}\right)$ of each SNP with the most associated SNP (which is shown in purple). Gray indicates SNPs for which $r^{2}$ information was missing.

\section{Abbreviations}

AAHRPP: Association for the Accreditation of Human Research Protection Programs; AREG amphiregulin; BMI: body mass index; ER: estrogen receptor; ESR1: estrogen receptor 1; GWAS: genome-wide association study; HWE: Hardy-Weinberg equilibrium; INHBA: inhibin, beta A; INHBB: inhibin, beta B: IRB: institutional review board; LD: linkage disequilibrium; MAF: minor allele frequency; p53: protein 53; PTHLH: parathyroid hormone-like hormone; SNP: single nucleotide polymorphism; TGF: transforming growth factor; ZNF365: zinc finger protein 365; ZNF703: zinc finger protein 703.

\section{Competing interests}

The authors of this paper are 23andMe employees and own stock options in the company.

\section{Author's contributions}

$N E, G B, C B D, A K K$, JLM, DAH, UF, and JYT conceived and designed the experiments. NE and CBD analyzed the data. NE drafted the manuscript with contributions from all other authors.

\section{Acknowledgements}

We thank the customers of 23andMe for participating in this research and all the employees of 23andMe for contributing to the research.

Received: 14 December 2011 Accepted: 30 June 2012

Published: 30 June 2012

\section{References}

1. Boyd NF, Guo H, Martin LJ, Sun L, Stone J, Fishell E, Jong RA, Hislop G, Chiarelli A, Minkin S, Yaffe MJ: Mammographic density and the risk and detection of breast cancer. N Eng/J Med 2007, 356:227-236.

2. Baer HJ, Colditz GA, Rosner B, Michels KB, Rich-Edwards JW, Hunter DJ Willett WC: Body fatness during childhood and adolescence and incidence of breast cancer in premenopausal women: a prospective cohort study. Breast Cancer Res 2005, 7:R314-R325.

3. Magnusson C, Baron J, Persson I, Wolk A, Bergstrom R, Trichopoulos D, Adami HO: Body size in different periods of life and breast cancer risk in post-menopausal women. Int J Cancer 1998, 76:29-34.

4. van den Brandt PA, Spiegelman D, Yaun SS, Adami HO, Beeson L, Folsom AR, Fraser G, Goldbohm RA, Graham S, Kushi L, Marshall JR, Miller AB, Rohan T, Smith-Warner SA, Speizer FE, Willett WC, Wolk A, Hunter DJ: Pooled analysis of prospective cohort studies on height, weight, and breast cancer risk. Am J Epidemiol 2000, 152:514-527.

5. Eliassen AH, Colditz GA, Rosner B, Willett WC, Hankinson SE: Adult weight change and risk of postmenopausal breast cancer. JAMA 2006, 296:193-201.

6. Scutt D, Lancaster GA, Manning JT: Breast asymmetry and predisposition to breast cancer. Breast Cancer Res 2006, 8:R14

7. Kusano AS, Trichopoulos D, Terry KL, Chen WY, Willett WC, Michels KB: A prospective study of breast size and premenopausal breast cancer incidence. Int J Cancer 2006, 118:2031-2034.

8. Egan KM, Newcomb PA, Titus-Ernstoff L, Trentham-Dietz A, Baron JA, Willett WC, Stampfer MJ, Trichopoulos D: The relation of breast size to breast cancer risk in postmenopausal women (United States). Cancer Causes Control 1999, 10:115-118.

9. Lindstrom S, Vachon CM, Li J, Varghese J, Thompson D, Warren R, Brown J, Leyland J, Audley T, Wareham NJ, Loos RJ, Paterson AD, Rommens J, Waggott D, Martin LJ, Scott CG, Pankratz VS, Hankinson SE, Hazra A, Hunter DJ, Hopper JL, Southey MC, Chanock SJ, Silva IdS, Liu J, Eriksson L, Couch FJ, Stone J, Apicella C, Czene K, et al: Common variants in ZNF365 are associated with both mammographic density and breast cancer risk. Nat Genet 2011, 43:185-187.
10. Wade TD, Zhu G, Martin NG: Body mass index and breast size in women: same or different genes? Twin Res Hum Genet 2010, 13:450-454.

11. Eriksson N, Macpherson JM, Tung JY, Hon LS, Naughton B, Saxonov S, Avey L, Wojcicki A, Pe'er I, Mountain J: Web-based, participant-driven studies yield novel genetic associations for common traits. PLOS Genet 2010, 6:e1000993.

12. Tung JY, Do CB, Hinds DA, Kiefer AK, Macpherson JM, Chowdry AB, Francke U, Naughton BT, Mountain JL, Wojcicki A, Eriksson N: Efficient replication of over $\mathbf{1 8 0}$ genetic associations with self-reported medical data. PLOS ONE 2011, 6:e23473.

13. Henn B, Hon L, Macpherson JM, Eriksson N, Saxonov S, Pe'er I, Mountain $\mathrm{J}$ : Cryptic distant relatives are common in both isolated and cosmopolitan genetic samples. PLOS ONE 2012, 7(4):e34267.

14. Eriksson N, Tung JY, Kiefer AK, Hinds DA, Francke U, Mountain JL, Do CB Novel associations for hypothyroidism include known autoimmune risk loci. PLOS ONE 2012, 7(4):e34442.

15. Altshuler D, Durbin RM, Abecasis GR, Bentley DR, Chakravarti A, Clark AG Collins FS, De La Vega FM, Donnelly P, Egholm M, Flicek P, Gabriel SB, Gibbs RA, Knoppers BM, Lander ES, Lehrach H, Mardis ER, McVean GA, Nickerson DA, Peltonen L, Schafer AJ, Sherry ST, Wang J, Wilson R, Gibbs RA, Deiros D, Metzker M, Muzny D, Reid J, Wheeler D, et al: A map of human genome variation from population-scale sequencing. Nature 2010, 467:1061-1073.

16. Browning SR, Browning BL: Rapid and accurate haplotype phasing and missing-data inference for whole-genome association studies by use of localized haplotype clustering. Am J Hum Genet 2007 81:1084-1097.

17. Abecasis G, Fuchsberger C: minimac. http://genome.sph.umich.edu/ wiki/minimac

18. Wigginton JE, Cutler DJ, Abecasis GR: A note on exact tests of Hardy-Weinberg equilibrium. Am J Hum Genet 2005, 76(5):887-893.

19. Ringberg A, Bageman E, Rose C, Ingvar C, Jernstrom $\mathrm{H}$ : Of cup and bra size: reply to a prospective study of breast size and premenopausal breast cancer incidence. Int J Cancer 2006, 119:2242-2243.

20. Garcia MJ, Pole JC, Chin SF, Teschendorff A, Naderi A, Ozdag H, Vias M, Kranjac T, Subkhankulova T, Paish C, Ellis I, Brenton JD, Edwards PA, Caldas C: A 1 Mb minimal amplicon at 8p11-12 in breast cancer identifies new candidate oncogenes. Oncogene 2005, 24:5235-5245.

21. Sircoulomb F, Nicolas N, Ferrari A, Finetti P, Bekhouche I, Rousselet $E_{\text {, }}$ Lonigro A, Adelaide J, Baudelet E, Esteyries S, Wicinski J, Audebert S, Charafe-Jauffret E, Jacquemier J, Lopez M, Borg JP, Sotiriou C, Popovici C, Bertucci F, Birnbaum D, Chaffanet M, Ginestier C: ZNF703 gene amplification at $8 \mathrm{p} 12$ specifies luminal $\mathrm{B}$ breast cancer. $E M B O M O$ Med 2011, 3:153-166

22. Holland DG, Burleigh A, Git A, Goldgraben MA, Perez-Mancera PA, Chin SF, Hurtado A, Bruna A, Ali HR, Greenwood W, Dunning MJ, Samarajiwa S, Menon S, Rueda OM, Lynch AG, McKinney S, Ellis IO, Eaves CJ, Carroll JS, Curtis C, Aparicio S, Caldas C: ZNF703 is a common Luminal B breast cancer oncogene that differentially regulates luminal and basal progenitors in human mammary epithelium. EMBO Mol Med 2011, 3:167-180.

23. Kwek SS, Roy R, Zhou H, Climent J, Martinez-Climent JA, Fridlyand J, Albertson DG: Co-amplified genes at $8 p 12$ and $11 q 13$ in breast tumors cooperate with two major pathways in oncogenesis. Oncogene 2009, 28:1892-1903.

24. Charpentier AH, Bednarek AK, Daniel RL, Hawkins KA, Laflin KJ, Gaddis S, MacLeod MC, Aldaz CM: Effects of estrogen on global gene expression: identification of novel targets of estrogen action. Cancer Res 2000, 60:5977-5983.

25. Reis FM, Luisi S, Carneiro MM, Cobellis L, Federico M, Camargos AF, Petraglia F: Activin, inhibin and the human breast. Mol Cell Endocrinol 2004, 225:77-82.

26. Mylonas I: Inhibin-alpha, -betaA and -betaB subunits in uterine non-endometrioid carcinomas: Prognostic significance and clinical implications. Eur J Cancer 2010, 46:2485-2493.

27. Sjöholm K, Palming J, Lystig TC, Jennische E, Woodruff TK, Carlsson B, Carlsson LM: The expression of inhibin beta $B$ is high in human adipocytes, reduced by weight loss, and correlates to factors implicated in metabolic disease. Biochem Biophys Res Commun 2006, 344:1308-1314. 
28. Stacey SN, Sulem P, Zanon C, Gudjonsson SA, Thorleifsson G, Helgason A, Jonasdottir A, Besenbacher S, Kostic JP, Fackenthal JD, Huo D,

Adebamowo C, Ogundiran T, Olson JE, Fredericksen ZS, Wang X, Look MP, Sieuwerts AM, Martens JW, Pajares I, Garcia-Prats MD, Ramon-Cajal JM, de Juan A, Panadero A, Ortega E, Aben KK, Vermeulen SH, Asadzadeh F, van Engelenburg KC, Margolin S, et al: Ancestry-shift refinement mapping of the C6orf97-ESR1 breast cancer susceptibility locus. PLOS Genet 2010, 6:e1001029.

29. Turnbull C, Ahmed S, Morrison J, Pernet D, Renwick A, Maranian M, Seal S, Ghoussaini M, Hines S, Healey CS, Hughes D, Warren-Perry M, Tapper W, Eccles D, Evans DG, Hooning M, Schutte M, van den Ouweland A, Houlston R, Ross G, Langford C, Pharoah PD, Stratton MR, Dunning AM, Rahman N, Easton DF: Genome-wide association study identifies five new breast cancer susceptibility loci. Nat Genet 2010, 42:504-507.

30. Ghoussaini M, Fletcher O, Michailidou K, Turnbull C, Schmidt MK, Dicks E, Dennis J, Wang Q, Humphreys MK, Luccarini C, Baynes C, Conroy D, Maranian M, Ahmed S, Driver K, Johnson N, Orr N, Dos SantosSilva, I, Waisfisz Q, Meijers-Heijboer H, Uitterlinden AG, Rivadeneira F, Hall P, Czene K, Irwanto A, Liu J, Nevanlinna H, Aittomäki K, Blomqvist C, Meindl $A$, et al: Genome-wide association analysis identifies three new breast cancer susceptibility loci. Nat Genet 2012, 44:312-318.

31. Hens JR, Dann P, Zhang JP, Harris S, Robinson GW, Wysolmerski J: BMP4 and PTHrP interact to stimulate ductal outgrowth during embryonic mammary development and to inhibit hair follicle induction. Development 2007, 134:1221-1230.

32. Thiede MA, Rodan GA: Expression of a calcium-mobilizing parathyroid hormone-like peptide in lactating mammary tissue. Science 1988, 242:278-280.

33. LaMarca HL, Rosen JM: Estrogen regulation of mammary gland development and breast cancer: amphiregulin takes center stage. Breast Cancer Res 2007, 9:304.

34. Ciarloni L, Mallepell S, Brisken C: Amphiregulin is an essential mediator of estrogen receptor alpha function in mammary gland development. Proc Natl Acad Sci USA 2007, 104:5455-5460.

35. Speliotes EK, Willer CJ, Berndt SI, Monda KL, Thorleifsson G, Jackson AU, Allen HL, Lindgren CM, Luan J, Magi R, Randall JC, Vedantam S, Winkler TW, Qi L, Workalemahu T, Heid IM, Steinthorsdottir V, Stringham HM, Weedon MN, Wheeler E, Wood AR, Ferreira T, Weyant RJ, Segre AV, Estrada K, Liang L, Nemesh J, Park JH, Gustafsson S, et al: Association analyses of 249,796 individuals reveal 18 new loci associated with body mass index. Nat Genet 2010, 42:937-948.

doi:10.1186/1471-2350-13-53

Cite this article as: Eriksson et al: Genetic variants associated with breast size also influence breast cancer risk. BMC Medical Genetics 2012 13:53.

\section{Submit your next manuscript to BioMed Central} and take full advantage of:

- Convenient online submission

- Thorough peer review

- No space constraints or color figure charges

- Immediate publication on acceptance

- Inclusion in PubMed, CAS, Scopus and Google Scholar

- Research which is freely available for redistribution

Submit your manuscript at www.biomedcentral.com/submit
() Biomed Central 